\title{
O ESTRANGEIRO PARA A ACADEMIA DE ARTES E CIÊNCIAS \\ CINEMATOGRÁFICAS DE HOLLYWOOD: OS VENCEDORES DO OSCAR DE MELHOR FILME EM LÍNGUA ESTRANGEIRA (2005 - 2014) \\ THE FOREIGN ACCORDING TO ACADEMY OF MOTION PICTURES ARTS AND SCIENCES: ACADEMY AWARDS FOR BEST FOREIGN LANGUAGE FILM (2005 - 2014)
}

\author{
Rafael Jose Bona \\ Doutorando em Comunicação e Linguagens (UTP) \\ Docente e Pesquisador da Universidade do Vale do Itajaí (UNIVALI), \\ E-mail: bona.professor@gmail.com \\ Jéssica Pereira Frazão \\ Graduanda em Produção Audiovisual (UNIVALI) \\ Bolsista de Pesquisa de Iniciação Científica \\ jessifrazao@hotmail.com
}

\section{RESUMO}

O mais conhecido prêmio do cinema mundial, o Oscar (Academy Awards), sempre representou um objeto de desejo para os cinemas de todas as nações. A inscrição de um longa-metragem na categoria de Melhor Filme em Língua Estrangeira é, no mínimo, uma questão política. Esta pesquisa constitui-se de uma análise fílmica dos filmes vencedores da categoria de Melhor Filme em Língua Estrangeira, no Oscar de 2005 a 2014. Com os resultados alcançados, foi possível observar o entendimento que a Academia de Hollywood faz do estrangeiro no cinema. Além disso, foi possível ter a compreensão sobre o processo de escolha de um filme, em detrimento de outros, e investigar se há características comuns aos longa-metragens vencedores.

Palavras-chave: Cinema. Oscar. Filme estrangeiro. Prêmios da Academia.

\section{ABSTRACT}

The most well-known prize in the world cinema, Oscar (Academy Awards), has always been an object of desire to worldwide filmmakers. Registration of a feature film in the Best Foreign Language Film category is, at least, a political matter. This research's aim was to analyze Best Foreign Language winner films from 2005 to 2014. Consistent with these results, it was 
possible to understand the meaning of motion pictures produced outside United States of America to the Academy of Hollywood. Furthermore, it was possible to comprehend the process of choosing a movie over others and that there are common characteristics shared by films winners.

Keywords: Cinema. Oscar. Foreign Film. Academy Awards.

\section{INTRODUÇÃO}

É possível perceber que o cinema tenha sido, dentre todas as formas de arte, a que mais rapidamente se espalhou. Consequência disso são os diversos e variados espetáculos e noites de gala que visam premiar filmes, diretores, atores e pessoas envolvidas no meio. Os Estados Unidos ocupa um lugar especial na produção de filmes e no reconhecimento de tudo envolvido com o cinema, dentro e fora do país, em diferentes categorias, e por motivos diversos. Desde menções honrosas às referências de fotografia fílmica e técnica. Nesse sentido, o prêmio Oscar (Academy Awards), entregue anualmente pela Academia de Artes e Ciências Cinematográficas (Academy of Motion Picture Arts and Sciences), desde o final dos anos 1920, faz reconhecimento aos melhores profissionais da área cinematográfica anualmente, como atores, diretores, roteiristas, dentre outros e tornou-se sinônimo de status e, por isso mesmo, transformou-se em um prêmio cobiçado.

Existe, dentro das 25 categorias do Oscar, a de Melhor Filme em Língua Estrangeira. Esta categoria, apesar de bastante conhecida, não existia nos primeiros anos do Oscar. Entre 1948 e 1956, a Academia reconhecia os filmes estrangeiros presenteando-os com prêmios ditos Especiais/Honorários. Entretanto, não havia uma regularidade e os filmes não eram competitivos, já que apenas um longa-metragem era indicado como o homenageado do ano. Foi apenas a partir de 1957 que a Academia se preocupou em criar um prêmio ao mérito, e este vem sendo entregue desde então. Dentre os 66 prêmios já entregues pela Academia, desde 1948 (até o ano de 2015), 53 foram filmes europeus, 5 asiáticos, 3 africanos e 3 americanos (com exclusão dos Estados Unidos). Segundo Kraus et al. (2008) é possível prever os premiados do Oscar nesta categoria por meio da base de dados online disponível no IMDB (Internet Movie Database). Esta previsão pode ser determinada pela comunicação estrutural da comunidade do IMDB, bem como pela especulação no relacionamento entre a comunicação intensiva existente sobre determinado filme e o desempenho do mesmo nas bilheterias. 
Em linhas gerais, para figurar nesta categoria, antes de qualquer coisa, a obra cinematográfica precisa ser um longa-metragem produzido fora dos EUA, e com diálogos feitos a partir de um idioma predominantemente diferente da Língua Inglesa. No entanto, mais elementos perpassam a escolha dos filmes vencedores. Sabemos, por exemplo, que estes filmes são escolhidos de acordo com os critérios de cada país, pois a seleção se faz a partir de uma indicação oficial feita por uma comissão formada por membros do Governo, e estes escolhem um filme em detrimento dos outros da maneira que julgam ser mais adequada. No Brasil, por exemplo, isto é feito pelo Ministério da Cultura, ou seja, a escolha pode assumir um caráter político (LUSVARGUI, 2007).

O presente artigo tem por finalidade elaborar uma reflexão acerca do cinema, buscando entender a representatividade do estrangeiro para a Academia de Cinema de Hollywood, a partir de um período específico: os últimos anos (2005-2014).

\section{A REPRESENTAÇÃO NO CINEMA}

O conceito de representação vem sendo utilizado em diversos campos dos estudos culturais, a partir da década de 1960, o que inclui também o cinema. O termo vem do latim representationis, e refere-se a uma imagem capaz de reproduzir algo, lembra Soares (2007).

A raiz semântica do termo "representação" já sugere à ideia de uma reapresentação, sugerindo uma semelhança, figurativa (imagem), ou uma correspondência estrutural (diagrama), ou processual (narrativa ou encenação), que busca a re-presentificação do objeto, pela sua evocação ou simulação. (SOARES,2007, p. 2).

Para Hall (2003), as representações fazem parte de um sistema cultural repleto de significado, na qual entendemos e configuramos o mundo e apresentamos da nossa maneira para o outro. Nesse sentido, atribui-se, de forma ideológica, referenciais diversos para dar sentido e decifrar a maneira pela qual a sociedade atua.

É dentro dos sistemas de representação da cultura e através deles que nós "experimentamos o mundo": a experiência é o produto de nossos códigos de inteligibilidade, de nossos esquemas de interpretação. Consequentemente, não há experiência fora das categorias de representação ou da ideologia. A noção de que nossas cabeças estão lotadas de ideias falsas que, entretanto, podem ser totalmente dissipadas quando nos abrimos para o "real" como um momento de absoluta autenticação é provavelmente a concepção mais ideológica de todas. (HALL, 2003, p. 182). 
O papel da comunicação é um exemplo de como reproduzimos as representações. $\mathrm{O}$ estudo proposto por Douglas Kellner (2001), em seu livro “A cultura da mídia”, partindo de diálogos envolvendo a Escola de Frankfurt e os Estudos Culturais britânicos, reforça essa ideia, mostrando como somos influenciados pela cultura da imagem, em maior ou menor grau, por meio dos significados produzidos pelas representações, fornecendo modelos daquilo que o autor chamou de pedagogia cultural: "contribuem para nos ensinar como nos comportar e o que pensar e sentir, em que acreditar, o que temer e desejar - e o que não" (KELLNER, 2001, p. 10). Ainda, de acordo com o autor, as representações desempenham um papel muito importante na cultura da imagem, pois são elas que ajudam um determinado indivíduo a construir não só sua visão de mundo, mas “o senso de identidade, de sexo, consumando estilos e modo de vida, bem como pensamentos e ações sociopolíticas. " (KELLNER, 2001, p. 82).

Ao seguir a mesma lógica, não se deve classificar as representações como "ficções", já que são produzidas pelo próprio ser humano e constituem-se como práticas sociais (LIPPMANN, 2008). É possível, inclusive, entender a representação como uma dimensão estética, já que a mesma é também uma forma representativa, se levarmos em consideração a forma mimética da arte, como entendem Aristóteles e Platão, além do seu valor de autoreferencialidade. Representar é teatral, faz-se o papel de alguém, e se algo ou alguém está no lugar de outra coisa então é possível um indivíduo falar em nome do grupo ou um grupo falar em nome de outros. Este é, portanto, um princípio semiótico usado para compreender as representações que fazemos das coisas e dos indivíduos, e que está incluindo em discursos ideológicos e visões de mundo coletivas. (SHOHAT; STAM, 2006).

Em se tratando de algumas artes, é possível concebê-las como uma representação do real que engloba o visível e o não-visível (campo e o fora de campo), luz e sombra. Comolli (2008, p. 83) atribui maior força ao fora de campo do que ao próprio campo, pois engloba o visível como completude do não visível, envolvendo-o, penetrando-o. Foucault (2002) faz referência semelhante quando analisa o quadro "As Meninas", de Diego Velázquez. De acordo com a posição adotada pelo espectador, o sujeito pode atribuir outro significado, porque existe a invisibilidade da imagem e que se torna visível quando aos olhos do pintor. $\mathrm{O}$ quadro torna os personagens, assim como nós espectadores, de não-visíveis a visíveis na medida em se olha o reflexo no espelho. Segundo Foucault (2002, p. 21), "a representação pode se dar como pura representação". Neste caso, o quadro citado é, portanto, autoreferencial. 
Sendo assim, devemos compreender as representações como um sistema cultural absorvido de diferentes formas por diferentes grupos e que estes, por sua vez, constroem a partir de tais observações uma realidade vigente. As representações que fazemos da comunicação e da mídia possuem forte influência na nossa maneira de interpretação do mundo e, apesar de serem representações, não são mentira e nem verdade, constituem-se a partir do hibridismo realidade/representação formando uma unidade ou, em outras palavras, uma extensão do real (SANTOS, 2011). Representar é dar uma direção estética quando em forma mimética, é deixar o coletivo se sobressair em relação ao individual para auxiliar na construção de uma realidade deixando os interesses dos indivíduos serem a estância máxima de controle da questão. Funciona como espelho, já que reflete um sentido verdadeiro e, finalmente, engloba o visível e o não visível no campo artístico.

Representação é também relacionável à sétima arte. Seus elementos representativos e sua capacidade mimética aproxima o espectador à uma ideia de realidade. Bernardet (1980, p. 20), por exemplo, afirma que "a história do cinema é em grande parte a luta constante para manter ocultos os aspectos artificiais do cinema e para sustentar a impressão de realidade".

\subsection{O CINEMA HOLLYWOODIANO E O OSCAR}

Ao contextualizar a história do prêmio Oscar é preciso, primeiramente, mencionar a história da Academia de Ciências Cinematográficas de Hollywood Academy of Motion Picture Arts And Sciences. Em novembro de 1926, com a assinatura do Studio Basic Agreement, deu-se um acordo feito entre nove grandes estúdios cinematográficos estadunidenses e seus representantes técnicos fundamentais para a indústria cinematográfica, tais como carpinteiros, eletricistas, pintores, entre outros. Este acordo regulamentava as atividades, bem como fortalecia e organizava os diversos profissionais do setor. Um mês depois, o então presidente da MGM se reuniu com outras importantes pessoas públicas do meio a fim de tratar especificadamente do grupo artístico que compunha a indústria cinematográfica (roteiristas, atores e diretores) e que não tinham sido incluídos no Studio Basic Agreement (FILM REFERENCE, 2014, online). Essa conversa representou a concepção das ideias iniciais do que viria a ser a Academia. Criada em 1927, com o intuito de beneficiar a indústria e incentivar a produção de obras cinematográficas de alta qualidade técnica e estética, a Academia de Artes e Ciências Cinematográficas de Hollywood promoveu, dois anos mais tarde, a sua primeira cerimônia de premiação, durante um banquete 
no Hollywood Roosevelt Hotel. Entretanto, sem muita surpresa quanto aos ganhadores das estatuetas.

\begin{abstract}
No primeiro ano, os ganhadores do troféu iam para a noite de cerimônias já sabendo quem tinha ganhado em cada categoria. Depois, a Academia passou a liberar os ganhadores para a imprensa, que poderia estampar suas manchetes na manhã seguinte. Mas tudo mudou depois que o Los Angeles Times publicou a lista antes da premiação, estragando as surpresas. E assim, desde 1941, os envelopes são abertos apenas na cerimônia de entrega dos prêmios. (BORGO; FORNALI; HESSEL, 2009, p. 280).
\end{abstract}

A cerimônia, que ocorre anualmente, já realizou até o momento oitenta e sete edições do Oscar (até o ano de 2015). É possível perceber o amadurecimento da cerimônia nessas mais de oito décadas, sempre buscando novas formas de se pensar o Oscar enquanto espetáculo. Durante sua história, a Academia reuniu uma variedade enorme de rolos de filmes, fotografias e outros itens relacionáveis ao cinema. Essa preocupação com a preservação, história e memória do seu patrimônio material intensificou-se na década de 1950. A Academia contava nessa época com milhares de itens, indo desde filmes raros produzidos por George Méliès a outros filmes do primeiro cinema (HALL, 2013). Aos poucos, e por motivos financeiros, os ambiciosos projetos de resguardar a história do Oscar tornaram-se não mais o foco. A Academia, com sérios problemas nas finanças em decorrência das transformações ocorridas pelo Pós-guerra e pela censura do Comitê de Investigação de Atividades Antiamericanas ${ }^{1}$, precisava priorizar outras formas de lucro, e deu-se então, em 1953, a primeira transmissão da cerimônia do Oscar na televisão, ocorrida apenas nos Estados Unidos e no Canadá e, posteriormente, em 1969, em âmbitos internacionais. Com isso, a Academia conquistou números estrondosos na audiência e ganhou o prestígio e respeito do público, comparando-se aos níveis dos grandes eventos internacionais. (HAURELHUK, 2008).

Apesar da cerimônia em si obter índices absurdos de audiência, a Academia busca oferecer mais do que isso aos cinéfilos e entusiastas. A respeito da cultura fílmica, é possível visitar, em Beverly Hills, a biblioteca Margaret Herrick, que conta com grande acervo de livros, periódicos, roteiros e pôsteres, (bem como uma galeria online, aproximando estudiosos de outros países) aos que desejam saber mais do assunto e suas vertentes. Já o arquivo conta com um acervo em torno de 83.000 títulos, funcionando como referência enquanto preservação da arte cinematográfica. Partindo para outro viés, a Academia auxilia estudantes de cinema e de audiovisual, produtores independentes e também de outras áreas, dando-lhes oportunidades de participarem de programas educacionais sobre cinema, dentro e fora dos 
Estados Unidos. Além disso, financia festivais, organizações e programas universitários. (ACADEMY OF MOTION PICTURE ARTS AND SCIENCES, 2014, online).

\subsection{A CATEGORIA DE MELHOR FILME EM LÍNGUA ESTRANGEIRA}

Conforme já mencionado, a categoria de Melhor Filme em Língua Estrangeira foi criada em 1956, com o intuito de valorizar a produção de outros países. Ela pode ser considerada polêmica, confusa e imprevisível. Qualquer análise sobre a mesma deve considerar, dentre outras coisas, o próprio atual regimento da categoria (2013), que considera os seguintes aspectos: o critério da elegibilidade: o filme deve ser um longa-metragem produzido fora dos Estados Unidos e que tenha predominantemente diálogos em outro idioma que não o de língua inglesa; o filme deve ter sido concretizado por cidadãos do país em questão; quanto a submissão: cada país terá apenas um filme aceito na categoria e este deve ser convidado a submeter sua obra à Academia, portanto, muitos filmes de determinado país sequer chegarão a serem vistos e nem todos os países serão convidados. No Brasil, a divulgação ocorre a partir da decisão de pessoas ligadas ao meio audiovisual brasileiro. (ADOROCINEMA, 2014, online).

A seleção dos filmes que chega até Hollywood é feita por um comitê, organização ou júri local, dos quais fazem parte artistas e/ou pessoas ativas do meio cinematográfico. A lista dos comitês é anualmente renovada pela Academia, que a divulga em período específico. Quanto a pré-seleção, todos os filmes são submetidos ao comitê, e escolhidos de forma individual e secreta. Após isso, votam-se nos cinco melhores, e o voto restringe-se apenas aos membros da Academia. Dá-se então a decisão dos filmes selecionados, que serão revistos até que se tenha um vencedor. Torna-se proibida a divulgação do filme enquanto "finalista na categoria de melhor filme em língua estrangeira" até que seja liberada a lista pelos organizadores da cerimônia. (ACADEMY OF MOTION PICTURE ARTS AND SCIENCES, 2014, online).

O número de filmes participantes na categoria cresce a cada ano. Isso dificulta o processo de seleção porque exige-se um tempo considerável do comitê até que todos assistam a tudo. Desta maneira, o que ocorre é que "normalmente acaba sendo composto por profissionais que estejam afastados há algum tempo da atividade, aposentados ou inativos; normalmente mais sensíveis e resistentes a filmes com estéticas ou temáticas mais ousadas" (HAURELHUK, 2008, p. 79). Além disso, pode-se levar outros fatores em consideração para 
a complexa e dúbia escolha dos filmes finalistas na categoria de Melhor Filme em Língua Estrangeira como, por exemplo, o fato de que a escolha é feita muitas vezes por uma banca estadunidense, com valores culturais próprios. Como explicar uma análise e seleção feita em relação a um filme estrangeiro, que vá além da visão puramente técnica? O site Spoiler Movies (2014, online) ressalta que, para submeter mais facilmente um filme à Academia, "a fita deve ser antes de tudo universal, um consenso comercial, de crítica e bilheteria, de longo alcance, não só em território americano, mas necessariamente na Europa e no mundo". Esta pode ser uma possível explicação de alguns filmes nacionais não ficarem entre os finalistas, já que muitas vezes estão repletos de regionalismos, religiosidade e fatores culturais bastantes específicos.

\section{PROCEDIMENTOS METODOLÓGICOS E ANÁLISE DOS FILMES}

Este estudo classificou-se como exploratório, o que, segundo Medeiros (2006, p.41), "estabelece critérios, métodos e técnicas para a elaboração de uma pesquisa e visa orientar a formulação de hipóteses". Para chegar aos resultados pretendidos, dividiu-se a pesquisa em duas etapas: a primeira se deu com pesquisa bibliográfica e fontes secundárias. (MEDEIROS, 2006).

A segunda etapa se deu com a análise fílmica das obras selecionadas. Para Francis Vanoye e Anne Goliot-Lété (2002), este tipo de análise possui muito mais elementos possíveis de compreensão e debate (visual, sonoro, fílmico, etc.) em relação à uma análise apenas literária, que descreve "o escrito pelo escrito". Dessa maneira, percebe-se que o trabalho deve ser pensado de forma a atentar-se ao todo, assim como aos detalhes, aos elementos específicos que serão analisados, bem como os meios em que a obra conduz um espectador não analista. Segundo o autor "não é possível conduzir, elaborar, uma análise de filme apenas com base nas primeiras impressões. Mas seria errado separar radicalmente o produto da atividade de espectador 'comum' da análise." (VANOYE, GOLIOT-LÉTÉ, 2002, p. 13).

O universo desta pesquisa foi composto,então, por todos os dez filmes vencedores do Oscar de Melhor Filme em Língua Estrangeira, dos anos de 2005 a 2014. Assim, chegamos aos seguintes títulos: Mar Adentro, Infância Roubada, A Vida dos Outros, Os Falsários, A Partida, O Segredo dos Seus Olhos, em um Mundo Melhor, A Separação, Amor e A Grande 
Beleza. Os filmes foram analisados levando-se em consideração as características socioculturais dos seus países de origem. Os mesmos foram assistidos por meio das cópias em DVD lançadas no Brasil, bem como pelos serviços online oferecidos pela empresa estadunidense Netflix.

A partir desta seleção, a abordagem da pesquisa foi feita de forma qualitativa e quantitativa. Analisou-se tanto aspectos representativos referentes ao próprio país, aos Estados Unidos e estrangeirismos, quanto a fatores gerais do filme, como o gênero cinematográfico, a época em que o mesmo se passa, o tipo de narrativa, os aspectos pontuais dos personagens, como a quantidade de protagonistas e coadjuvantes, bem como se há personagens idosos ou infantis (fato este, importante, por já termos uma observação empírica em relação aos relatos já publicados pela imprensa sobre a relação de idosos e crianças em filmes premiados nesta categoria). Por fim, foram analisadas as características mais voltadas a relação do país e do diretor com o Oscar.

Elaborou-se um quadro que refere-se ao nome, ano de premiação na categoria de filme estrangeiro, diretor(a), país de origem e língua(s) identificadas às obras cinematográficas escolhidas para análise, para melhor visualização:

\section{Quadro 1: Filmes analisados}

\begin{tabular}{|c|c|c|c|c|}
\hline $\begin{array}{c}\text { Ano de } \\
\text { Premiação }\end{array}$ & Filme & Diretor & País & Língua falada no filme \\
\hline 2005 & Mar adentro (2004) & Alejandro Amenábar & Espanha & $\begin{array}{c}\text { Espanhol (algumas partes em } \\
\text { Catalão e Galego) }\end{array}$ \\
\hline 2006 & $\begin{array}{c}\text { Infância Roubada } \\
(2005)\end{array}$ & Gavin Hood & $\begin{array}{c}\text { África do } \\
\text { Sul }\end{array}$ & $\begin{array}{c}\text { Isotsitaal (algumas partes em } \\
\text { Africâner e Inglês) }\end{array}$ \\
\hline 2007 & $\begin{array}{c}\text { A Vida dos Outros } \\
(2006)\end{array}$ & $\begin{array}{c}\text { Florian Henckel von } \\
\text { Donnersmarck }\end{array}$ & Alemanha & Alemão \\
\hline 2008 & Os Falsários (2007) & Stefan Ruzowitzky & Áustria & Japonês \\
\hline 2009 & A Partida (2008) & Yojiro Takita & Japão & Argentina \\
\hline 2010 & $\begin{array}{c}\text { O Segredo dos Seus } \\
\text { Olhos (2009) }\end{array}$ & Juan José Campanella \\
\hline 2011 & $\begin{array}{c}\text { Em um Mundo Melhor } \\
(2010)\end{array}$ & Susanne Bier & Dinamarca & $\begin{array}{c}\text { Dinamarquês (algumas partes em } \\
\text { Sueco e Inglês) }\end{array}$ \\
\hline 2012 & A Separação (2011) & Asghar Farhadi & Irã & Prancês \\
\hline 2013 & Amor (2012) & Margaret Ménégoz & Áustria & Italiano \\
\hline 2014 & $\begin{array}{c}\text { A Grande Beleza } \\
(2013)\end{array}$ & Paolo Sorrentino & Itália & \\
\hline
\end{tabular}

Fonte: Os autores, a partir de dados recolhidos no sítio IMDB (2014, online). 
Antes de nos atermos às discussões dos resultados, apresentamos a seguir a ficha utilizada, norteadora da análise:

\section{Quadro 2: Elementos da análise dos filmes}

\begin{tabular}{|c|l|}
\hline \multicolumn{3}{|c|}{ ELEMENTOS DA ANÁLISE DOS FILMES } \\
\hline \multirow{2}{*}{ Análise dos personagens } & $\begin{array}{l}\text { Quantidade de Protagonistas: ( ) } 1 \text { ( )2 ( )3 ( )4 ( ) } 5 \text { ou mais } \\
\text { Quantidade de Coadjuvantes: ( ) 1 ( )2 ( )3 ( )4 ( )5 ou mais } \\
\text { Possui personagens idosos? ( )Sim ( )Não } \\
\text { Possui personagens infantis? ( )Sim ( ) Não }\end{array}$ \\
\hline Análise da narrativa & História: ( ) Época ( ) Contemporânea \\
\hline Análise das representações & $\begin{array}{l}\text { Existem representações do próprio país no filme? ( )Sim ( )Não } \\
\text { Existem representações dos Estados Unidos no filme? ( )Sim ( )Não } \\
\text { Existem representações de estrangeirismo no filme? ( )Sim ( )Não }\end{array}$ \\
\hline Análise do Oscar & $\begin{array}{l}\text { Quantidade de vezes em que o país em questão ganhou o Oscar na categoria } \\
\text { analisada: ( )1 ( )2 ( )3 ( )4 ( ) } 5 \text { ou mais } \\
\text { Quantidade de vezes em que o(a) diretor(a) do filme ganhou o Oscar em outras } \\
\text { categorias: ( ) } 0 \text { ( )1 ( )2 ( )3 ( )4 ( ) } 5 \text { ou mais }\end{array}$ \\
\hline
\end{tabular}

Fonte: Dados da Pesquisa

\section{RESULTADOS DA PESQUISA E DISCUSSÃO}

Os resultados apresentados neste artigo foram coletados por meio da análise dos 10 filmes vencedores do Oscar de Melhor Filme em Língua Estrangeira, de 2005 a 2014. As obras foram assistidas 2 vezes cada uma durante a realização do estudo, e a observação se deu de acordo com os apontamentos do Quadro 02. Os quadros a seguir referem-se aos resultados da análise feita em cada um dos 10 filmes selecionados para compor esta pesquisa, de acordo com suas especificações, podendo se tratar dos aspectos gerais das personagens do filme, das características da narrativa ou ainda, dos apontamentos representativos e de envolvimento com o Oscar.

Quadro 3: análise das características dos personagens

\begin{tabular}{|c|c|c|}
\hline \multicolumn{2}{|c|}{ CARACTERÍSTICAS DOS PERSONAGENS } \\
\hline Papel no filme: protagonista & Quantidade de filmes & Porcentagem \\
\hline 1 Protagonista & 5 & $50 \%$ \\
\hline 2 Protagonistas & 3 & $30 \%$ \\
\hline 3 Protagonistas & 1 & $10 \%$ \\
\hline 4 Protagonistas & 1 & $10 \%$ \\
\hline 5 ou mais protagonistas & 0 & $0 \%$ \\
\hline Papel no filme: Coadjuvante & Quantidade de filmes & Porcentagem \\
\hline
\end{tabular}




\begin{tabular}{|c|c|c|}
\hline 1 Coadjuvante & 0 & $0 \%$ \\
\hline 2 Coadjuvantes & 0 & $0 \%$ \\
\hline 3 Coadjuvantes & 0 & $0 \%$ \\
\hline 4 Coadjuvantes & 2 & $20 \%$ \\
\hline 5 ou mais coadjuvantes & 8 & $80 \%$ \\
\hline \multirow{2}{*}{ Possui personagens idosos? } & Quantidade de filmes & Porcentagem \\
\cline { 2 - 3 } & 7 & $70 \%$ \\
\hline \multirow{2}{*}{ Possui personagens infantis? } & Quantidade de filmes & Porcentagem \\
\cline { 2 - 3 } & 6 & $60 \%$ \\
\hline
\end{tabular}

Fonte: Dados da Pesquisa

No quadro 3, observou-se que em metade dos filmes, há apenas 1 personagem protagonista, enquanto que para o papel de coadjuvante, a maioria utiliza-se de 5 ou mais (80\%). Ainda em relação aos papeis, existe um número significativo de personagens idosos $(70 \%)$ e personagens infantis $(60 \%)$. Isso mostra a preferência da Academia às narrativas que tragam personagens nesses perfis, assim como afirma Ewald Filho (2003) sobre a tradição da Academia premiar os filmes estrangeiros com essas características. Crianças e idosos tendem a emocionar o espectador e carregam em si um caráter internacionalizado, singular, e ao mesmo tempo, presente em todas as culturas.

\section{Quadro 4: Análise das Características Narrativas}

\begin{tabular}{|c|c|c|}
\hline \multicolumn{3}{|c|}{ ANÁLISE DA NARRATIVA } \\
\hline Gênero do filme & Quantidade de filmes & Porcentagem \\
\hline Drama & 10 & $100 \%$ \\
\hline Suspense & 0 & $0 \%$ \\
\hline Comédia & 1 & $10 \%$ \\
\hline Romance & 2 & $20 \%$ \\
\hline Ficção Científica & 0 & $0 \%$ \\
\hline Crime & 2 & $20 \%$ \\
\hline Tipo de narrativa & Quantidade de filmes & Porcentagem \\
\hline Linear & 5 & $50 \%$ \\
\hline Não linear & 5 & Porcentagem \\
\hline História & Quantidade de filmes & $40 \%$ \\
\hline De época & 4 & $70 \%$ \\
\hline Contemporânea & 7 & $50 \%$ \\
\hline
\end{tabular}

Fonte: Dados da Pesquisa

A Quadro 4 apresentou o gênero Drama como favorito absoluto para ganhar um Oscar de Melhor Filme Estrangeiro. É importante ressaltar que não necessariamente a filmografia analisada encaixou-se apenas em um gênero, podendo ser categorizada em até dois deles. Mas, o gênero Drama esteve presente em todos os filmes, o que mostra a preferência dos avaliadores. Ainda em relação à narrativa, 70\% dos filmes analisados são 
contemporâneos, e há um equilíbrio na linearidade ou não na maneira de se contar uma história (ambos 50\%).

\section{Quadro 5: Análise das Representações}

\begin{tabular}{|l|c|c|}
\hline \multicolumn{2}{|c|}{ ANÁLISE DAS REPRESENTAÇÕES } \\
\hline \multicolumn{1}{|c|}{ Questões } & Quantidade de filmes & Porcentagem \\
\hline Existem representações do próprio país no filme? & 4 & $40 \%$ \\
\hline Existem representações dos Estados Unidos no filme? & 0 & $0 \%$ \\
\hline Existem representações de estrangeirismo no filme? & 2 & $20 \%$ \\
\hline
\end{tabular}

Fonte: Dados da Pesquisa

A partir dos dados apresentados tem-se em $40 \%$ dos filmes analisados a existência de representações do próprio país. Exemplo disso é a exaltação de Roma em diversos momentos do filme italiano $A$ Grande Beleza. A capital italiana foi tão necessária à narrativa quanto o personagem protagonista. Ainda nesse sentido, não houve representações dos Estados Unidos na filmografia analisada, o que mostra que fazer referência ao país do Oscar e seu American Way of Life não são atributos que interfiram na escolha. Por fim, apenas $20 \%$ dos filmes mostraram representações quanto ao sentido de estrangeiro ou estrangeirismo, o que reforça a necessidade de que a obra possua caráter internacional.

\section{Quadro 6: Análise da Relação Filme/Diretor /Oscar}

\begin{tabular}{|c|c|c|}
\hline \multicolumn{3}{|l|}{ '2 } \\
\hline Questões & Quantidade de Filmes & Porcentagem \\
\hline $\begin{array}{l}\text { Quantidade de vezes em que o(a) diretor(a) do filme ganhou o } \\
\text { Oscar em outras categorias: }\end{array}$ & 0 & $0 \%$ \\
\hline $\begin{array}{l}\text { Quantidade de vezes em que o país em questão ganhou o Oscar } \\
\text { na categoria analisada: }\end{array}$ & Quantidade de filmes & Porcentagem \\
\hline 1 & 2 & $20 \%$ \\
\hline 2 & 3 & $30 \%$ \\
\hline 3 & 2 & $20 \%$ \\
\hline 4 & 2 & $20 \%$ \\
\hline 5 ou mais & 1 & $10 \%$ \\
\hline
\end{tabular}

Fonte: Dados da Pesquisa

A relação Oscar e filme estrangeiro revelou que o diretor da obra escolhida pouco importa aos avaliadores, interessando muito mais o roteiro e a técnica reunidos. A análise mostrou também que não há uma regra na escolha da obra cinematográfica por se tratar de um país já com um histórico de Oscars, como é o caso da Itália, que até o momento ganhou 13 
vezes o prêmio na categoria analisada. Portanto, o país não importa à Academia, e sim, se o filme conseguirá ou não ter uma linguagem universal, no julgamento deles.

\section{CONSIDERAÇÕES FINAIS}

Este estudo teve por finalidade analisar os dez últimos filmes vencedores na categoria de Melhor Filme em Língua Estrangeira (2005 a 2014). Com os resultados alcançados, foi possível refletir sobre as características dos personagens, narrativas, representações e da relação Oscar/Filme Estrangeiro, comparando-os e chegando em uma ideia aproximada do que a Academia de Ciências Cinematográficas de Hollywood pensa de um filme estrangeiro. Os resultados apontam para uma tendência em preferir filmes que tenham personagens idosos e/ou infantis, já que se entende que tais personagens carregam consigo um caráter universal, o que aumenta a aceitação da obra em diferentes culturas.

Espera-se contribuir nos estudos referentes ao Oscar, mais importante prêmio do cinema e que merece atenção especial devido ao seu valor, acima de tudo simbólico. Além disso, os filmes estrangeiros (produzidos fora dos Estados Unidos) são bastantes significativos e devem ser pensados de forma atenta, visto à complexidade de suas narrativas e personagens, formas diferenciadas de se pensar a técnica e acima de tudo, ao valor cultural único presente em cada uma das películas analisadas.

As limitações desta pesquisa relacionam-se a pouca bibliografia especializada na área. Ainda que existam algumas obras que tratem do prêmio Oscar e da Academia, em relação ao Melhor Filme Estrangeiro, pouca coisa se encontra, dificultando traçar um perfil mais consistente sobre a forma de se pensar a categoria em si. Deixa-se aqui como sugestão de pesquisa futura a continuação da análise aos anos seguintes, ou ainda às décadas passadas, para se fazer comparativos e análises sobre o mesmo objeto de estudo.

\section{NOTAS}

1 O Comitê de Investigação de Atividades Antiamericanas obrigou os estúdios a fecharem suas salas de cinema e vivia em constante perseguição a qualquer cidadão que tivesse ligações com o comunismo. Isso levou a denúncia de diversos profissionais do cinema, que foram desligados e somente voltaram a ativa no final da década de 1950. 


\section{REFERÊNCIAS}

ACADEMY OF MOTION PICTURE ARTS AND SCIENCES. Annual Report 2013. Disponível em: <https://www.oscars.org/about/annualreport>. Acessado em: 14 ago. 2014.

ACADEMY OF MOTION PICTURE ARTS AND SCIENCES. Special Rules For The Best Foreign Language Film Award. Disponível em: <http://www.oscars.org/awards/academ yawards/rules/87/pdf/87aa_rules.pdf $>$. Acessado em: 14 ago. 2014.

ADOROCINEMA. Disponível em: < http://www.adorocinema.com>. Acessado em: 17 ago. 2014.

BERNARDET, J-C. O que é cinema. Coleção Primeiros Passos. São Paulo: Brasiliense, 1980.

BORGO, É.; FORNALI, M.; HESSEL, M. Almanaque do cinema. Rio de Janeiro: Ediouro, 2009.

COMOLLI, J-L. Ver e poder: a inocência perdida: cinema, televisão, ficção, documentário. Belo Horizonte, UFMG, 2008.

EWALD FILHO, R. O Oscar e eu. São Paulo: Companhia Editora Nacional, 2003.

FILM REFERENCE. Academy Awards - Early History Disponível em: $<$ http://www.film reference.com/encyclopedia/Academy-Awards-Crime-Films/Academy-Awards-EARLYHISTORY.html\#ixzz3AJb9WoJy>. Acessado em: 13 ago. 2014.

FOUCAULT, M. As palavras e as coisas. São Paulo, Martins Fontes, 2002.

IMDB. Internet Movie Database - Oscar Best Foreign Language Film. Disponível em: http://www.imdb.com/list/ls051677536, acessado em 18 ago. 2014.

KRAUS, J.; NANN, S.; SIMON, D..; FISCHBACH, K; GLOOR, P. Predicting movie success and Academy Awards through sentiment and social network analysis. University of Cologne, 2008.

HALL, B. Oh, Pioneers! The Academy's Embrace of Early Film History, 1945-51. The Moving Image. Volume 13, n. 1, p. 185-193. University of Minnesota Press, 2013.

HALL, S. Dá diáspora: identidades e mediações culturais. Belo Horizonte: Editora da UFMG, 2003.

HAURELHUK, F. S. O Oscar foi para... Entendendo o maior prêmio cinematográfico mundial e sua relação com a cinematografia brasileira. Monografia de Graduação em Comunicação Social (Habilitação Cinema). Universidade Federal Fluminense, Niterói, RJ, 2008 .

KELLNER, D. A Cultura da mídia. Bauru, SP: Edusc, 2001.

LIPPMANN, W. Opinião pública. Editora Vozes: Petrópolis, 2008. 
LUSVARGUI, L. Oscar, internacionalização e cinema brasileiro: o diálogo possível entre o não ser e ser outro. Cadernos de Ciências Humanas - Especiaria. v. 10, n.17, jan./jun., 2007, p. 177-190.

MEDEIROS, J. B. Redação científica: a prática de fichamentos, resumos, resenhas. 8a ed. São Paulo: Atlas, 2006.

SANTOS, D. V. C. dos. Acerca do conceito de Representação. Revista de Teoria da História. Ano 3, n 6, Goiânia, Dez. 2011. p. 27-53.

SHOHAT, E.; STAM, R. Crítica da imagem eurocêntrica. São Paulo: Cosac Naify, 2006.

SOARES, M. C. Representações da cultura midiática: para a crítica de um conceito primordial. In: Anais... $17^{\circ}$ ENCONTRO DA COMPÓS (ASSOCIAÇÃO NACIONAL DE PROGRAMAS DE PÓS-GRADUAÇÃO EM COMUNICAÇÃO. 2007, Universidade Tuiuti do Paraná, Curitiba/PR.

SPOILER MOVIES. Disponível em: <http://spoilermovies.com.br/2014/07/09/o-brasil-e-acopa-do-cinema-o-oscar-2015>. Acessado em: 19 ago. 2014.

VANOYE, F.; GOLIOT- LÉTÉ, A. Ensaio sobre a análise fílmica. $2^{\mathrm{a}}$ ed. Campinas, SP. Papirus: 2002. (Coleção Ofício de arte e forma). 